\title{
Thermal Density Factor Analysis of Proton Exchange Membrane by Using Cfd
}

\author{
Vinoth Kumar.S, Dr.P. Rajendran \\ ME-THERMAL ENGINEERING RVS College of Engineering and Technology Coimbatore, India \\ Dean, Mechanical engineering RVS College of Engineering and Technology Coimbatore, India
}

\begin{abstract}
The objective of the project is to analyze Proton Exchange Membrane (PEM) Fuel Cell model numerically to understand the performance of the Fuel Cell model in various design and operating parameters which is difficult to analyze through the experiment. The numerical analysis was performed on single channel fuel cell which has INTERDIGIT rectangular flow path and also analysis was performed by varying the cross section like semicircular and triangular flow channel. After completing the study of analysis of the single channels, the numerical analysis work was performed on original PEMFC model which is used in fuel cell laboratory. Various analyses were carried out for the model by varying the parameters like varying the pressure, temperature. After varying the flow parameters similar procedure was followed for the analysis of various INTERDIGIT models with semicircular and triangular cross section and the performance of the models. The results show that the performance of the PEM Fuel Cell model is improved by decreasing the temperature and by increasing the operating pressure and by using semicircular and triangular flow channels compared with rectangular channel.
\end{abstract}

Key words; fuell cell,pem,comparission, serpentine, optimization,fea,cfd.

\section{Introduction}

\subsection{INTRODUCTION OF FUEL CELL}

A fuel cell is a device that converts the chemical energy from a fuel into electricity through a chemical reaction with oxygen or another oxidizing agent. Hydrogen is the most common fuel, but hydrocarbons such as natural gas and alcohols like methanol are sometimes used. Fuel cells are different from batteries in that they require a constant source of fuel and oxygen to run, but they can produce electricity continually for as long as these inputs are supplied. Fuel cells come in many varieties; however, they all work in the same general manner. They are made up of three adjacent segments: the anode the electrolyte, and the cathode. Two chemical reactions occur at the interfaces of the three different segments. The net result of the two reactions is that fuel is consumed, water or carbon dioxide is created, and an electric current is created, which can be used to power electrical devices, normally referred to as the load.

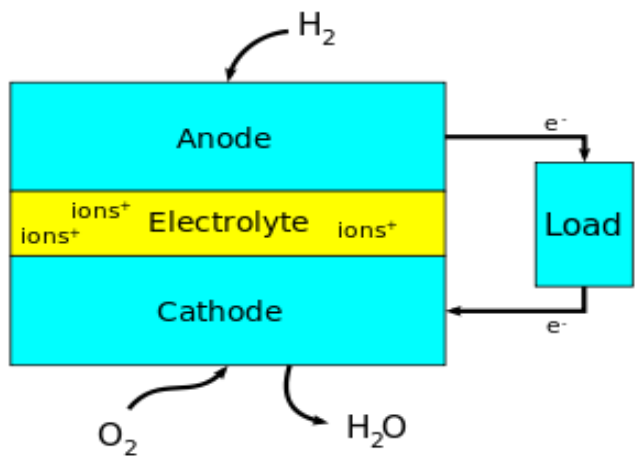

Figure 1.1 fuel cell 


\section{Methodology :}

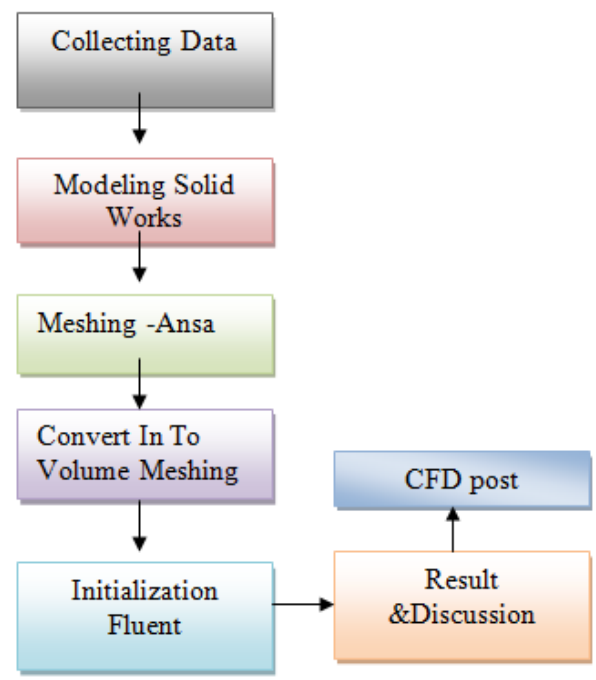

\subsection{STEPS FOLLOWED IN PEM FUEL CELL IN DIFFERENT FLOWS}

Serpentine and Interdigitated type Flow Channel of PEM fuel cell by using SOLIDWORK software.

- Surface meshing the newly created solid models in ANSA software.

- Volume meshing in TGRID software.

- Analysis of the models using FLUENT software by changing input voltage.

- Result output in CFD POST software.

- Comparing the results obtained and finding out optimum channel shape for the best performance of fuel cell.

- Experimental verification of the above optimized values.

- Developing Numerical model of given values to define the modeling to generating it. our project constructing and testing validation details to be collecting from PSG -Coimbatore .

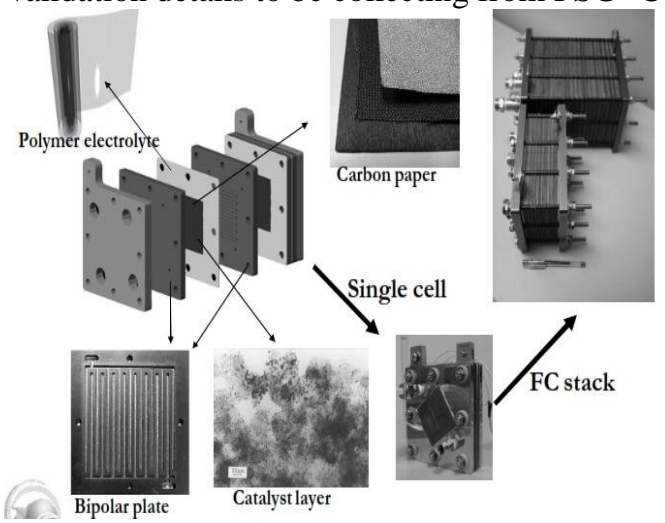

Figure 2 components of pem fuel cell in serpentine

\subsection{COLLECTION DATA}

\begin{tabular}{|c|c|}
\hline Width of flow path & $1 \mathrm{~mm}$ \\
\hline Depth of flow path & $1 \mathrm{~mm}$ \\
\hline Width of rib & $1 \mathrm{~mm}$ \\
\hline Depth of rib & $1 \mathrm{~mm}$ \\
\hline Size of bipolar plates & $80 \times 80 \times 10 \mathrm{~mm}$ \\
\hline Size of flow channel & $50 \times 50 \mathrm{~mm}$ \\
\hline GDL thickness & $0.3 \mathrm{~mm}$ \\
\hline Catalyst layer thickness & $0.08 \mathrm{~mm}$ \\
\hline Membrane layer thickness & $0.127 \mathrm{~mm}$ \\
\hline Porosity of GDL layer & 0.5 \\
\hline Operating pressure & $1 \mathrm{bar}$ \\
\hline Operating temperature & $50^{\circ} \mathrm{C}$ \\
\hline Hydrogen mass flow rate & $0.61 \mathrm{pm}$ \\
\hline Oxygen mass flow rate & $0.3 \mathrm{lpm}$ \\
\hline
\end{tabular}




\subsection{PROBLEM DEFINITION}

$>$ With interdigit flow fields, it can generally achieve more uniform reactants distribution with lower fuel consumption.

$>$ In this project, PEMFC with interdigit flow field is taken for analysis to improve its performance further.

\subsection{GENTRATE MODELING}

About the values to modeling in Solid works in varies cross section by using optimum engineering. Importing in to ansa while format can be used in *.IGS. See the figure 3.0
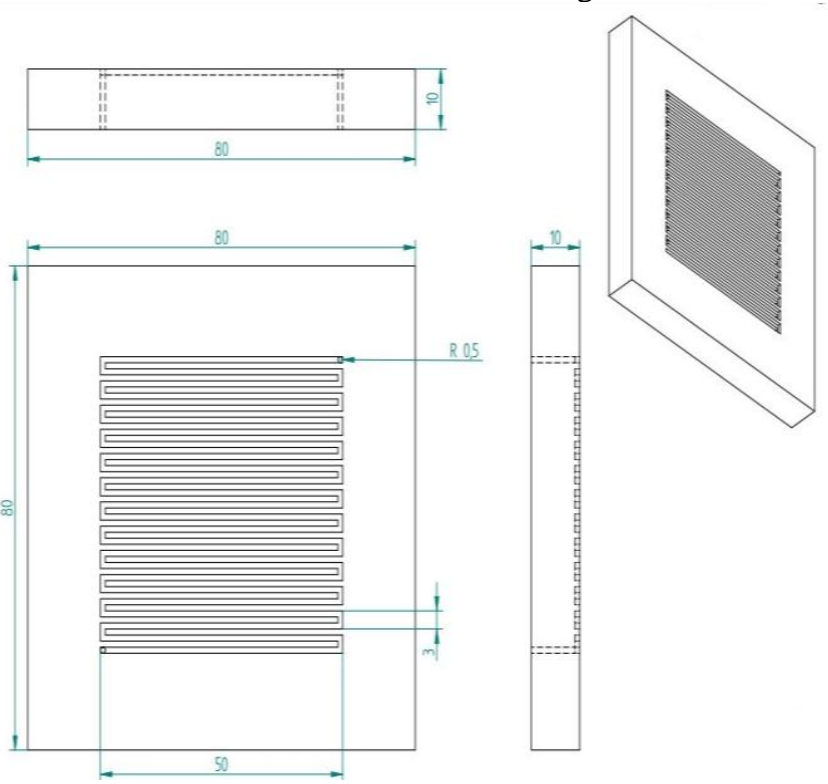

Figure 3 solid works modeling with dimensions

\subsection{GENERATE MESHING}

After modeling is done the process moves to meshing. The first step in meshing is setting of element size and numbers which will determine

the mesh count eventually accuracy. The type of element choose here is quad by under consideration of geometry shape. The following Fig 4.0 shows the element numbers of each layers.

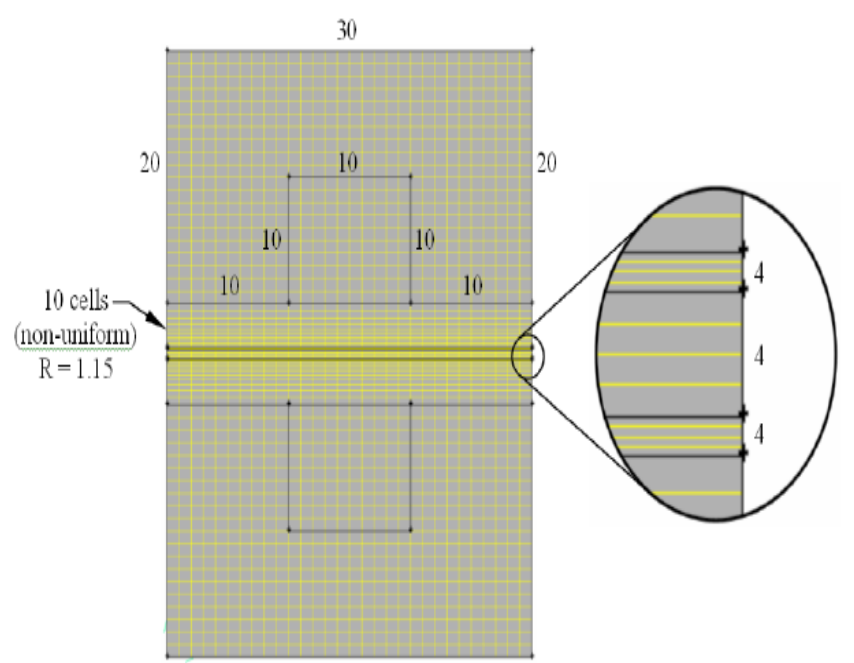

Figure 4 Generate Meshing 


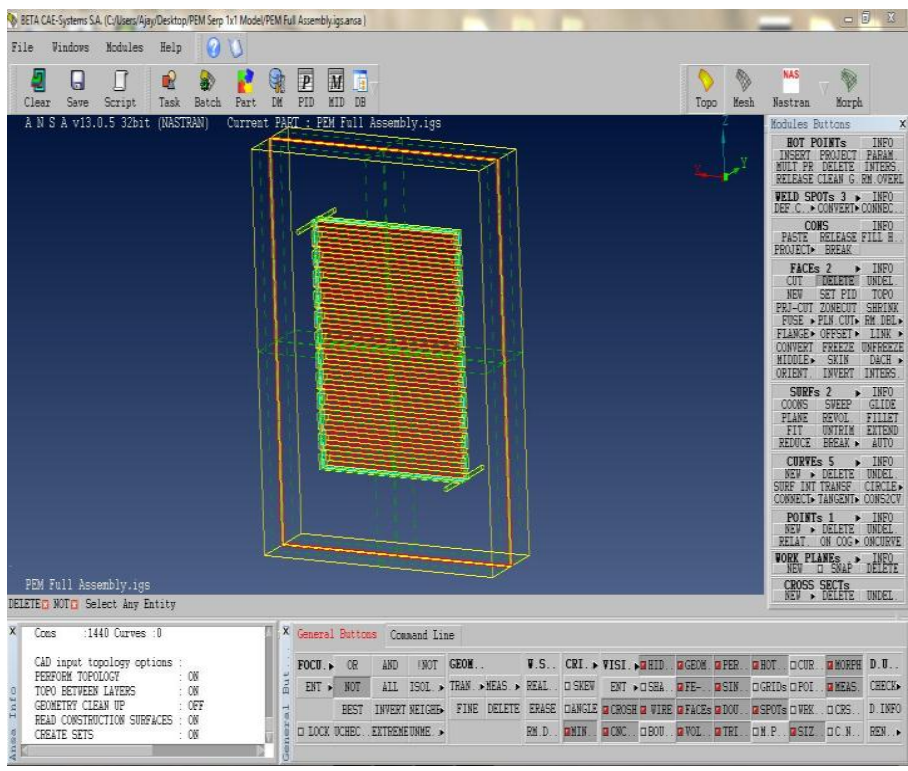

Figure 5.1 Generate Meshing -ANSA

\subsection{CONVERT IN TO VOLUME MESH}

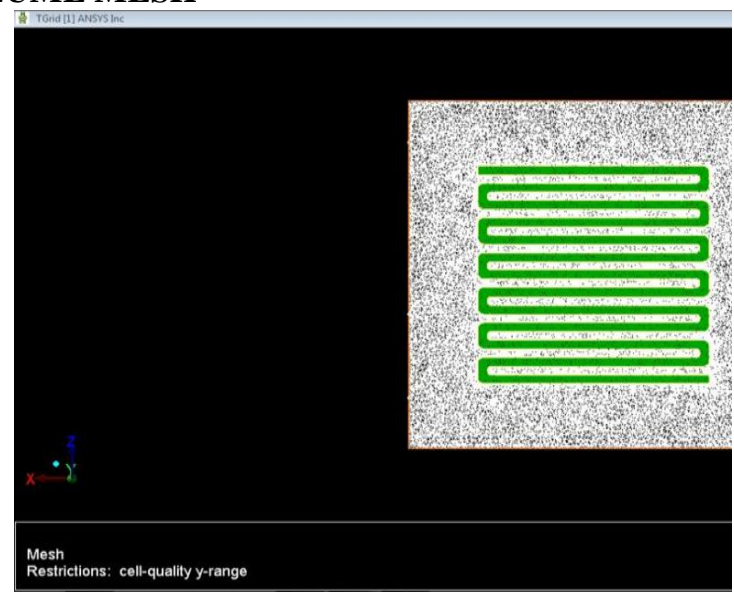

Figure 6 volume meshing in T-grid

our project constructively volume meshing in main purpose consuming

\subsection{BOUNDARY CONDITION}

FLUENT's PEM fuel cell add-on module requires that boundary and continuum zones be rigorously defined. At a minimum, the boundary zones that are required include the following:

- Inlet and outlet zones for the anode gas channel.

- Inlet and outlet zones for the cathode gas channel.

- Surfaces representing anode and cathode terminals.

Optional boundary zones that could be defined include any voltage jump surfaces, interior flow surfaces, or non-conformal interfaces that are required. The following continuum zones are also required:

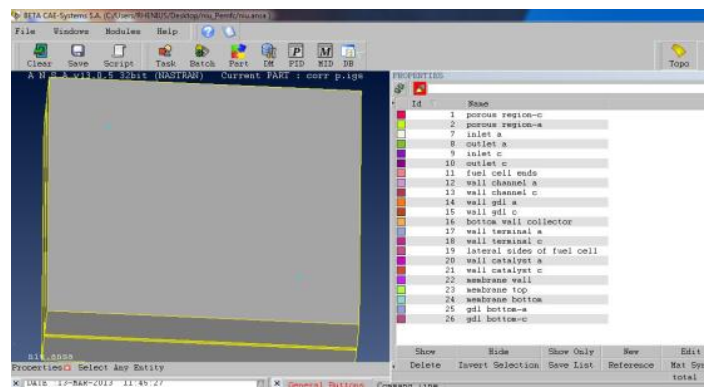

Figure 1.7 Boundary Layer 
- Flow channels for anode and cathode-sides.

- Anode and cathode current collectors.

- Anode and cathode gas diffusion layers.

- Anode and cathode catalyst layers.

- Electrolyte membrane.

\subsection{INITIALIZATION FLUENT}

There are several zones which must be specified in the boundary conditions panel are following below

- Anode inlet: Mass flow rate $=6 \mathrm{e}^{-7} \mathrm{~kg} / \mathrm{s}$, Temperature $=353 \mathrm{~K}$,

- Cathode inlet: Mass flow rate $=5 \mathrm{e}^{-6} \mathrm{Kg} / \mathrm{s}$,

Temperature $=353 \mathrm{~K}$,

- Cathode voltage terminal

- $\quad$ Electric potential $=0.75$

- Anode voltage terminal

- $\quad$ Electric potential $=0$

\section{Results And Discussion}

Results are obtained using FLUENT for the following set of operating conditions: temperature $=353 \mathrm{~K}$, pressure=2bar, FLUENT results are obtained for voltage as a function of current density is tabulated in Table 3.1 .

\begin{tabular}{|c|c|c|c|c|c|c|c|c|}
\hline \multirow[t]{2}{*}{ S.No. } & \multicolumn{2}{|c|}{$\begin{array}{l}\text { Electric } \\
\text { potential } \\
\text { (V) }\end{array}$} & \multicolumn{2}{|c|}{$\begin{array}{l}\text { Current density } \\
\qquad\left(\mathrm{A} / \mathrm{cm}^{2}\right) \\
\text { (Rec. channel) }\end{array}$} & \multicolumn{2}{|c|}{$\begin{array}{l}\text { Current density } \\
\qquad\left(\mathrm{A} / \mathrm{cm}^{2}\right) \\
\text { (V-channel) }\end{array}$} & \multicolumn{2}{|c|}{$\begin{array}{l}\text { Current density } \\
\qquad\left(\mathrm{A} / \mathrm{cm}^{2}\right) \\
\text { (U-channel) }\end{array}$} \\
\hline & $V_{\text {anode }}$ & $\mathrm{V}_{\text {cathode }}$ & $I_{\text {anode }}$ & Icathode $_{\text {cath }}$ & $I_{\text {anode }}$ & $I_{\text {cathode }}$ & $I_{\text {anode }}$ & $I_{\text {cathode }}$ \\
\hline 1 & 0 & 0 & 3.259 & 3.044 & 3.2765 & 3.2765 & 3.2984 & 3.2984 \\
\hline 2 & 0 & 0.05 & 3.236 & 3.042 & 3.2708 & 3.2708 & 3.2867 & 3.2867 \\
\hline 3 & 0 & 0.1 & 3.204 & 3.037 & 3.2591 & 3.2591 & 3.2725 & 3.2725 \\
\hline 4 & 0 & 0.2 & 3.107 & 2.982 & 3.2435 & 2435 & 3.2505 & 3.5673 \\
\hline 5 & 0 & 0.3 & 2.954 & 2.868 & 3.1645 & 3.1645 & 3.145 & 3.145 \\
\hline 6 & 0 & 0.4 & 2.695 & 2.625 & 2.9916 & 2.9916 & 2.9271 & 2.9271 \\
\hline 7 & 0 & 0.5 & 2.286 & 2.236 & 2.6225 & 2.6225 & 2.5026 & 2.5026 \\
\hline 8 & 0 & 0.6 & 1.706 & 1.683 & 1.908 & 1.908 & 1.954 & 1.954 \\
\hline 9 & 0 & 0.7 & 0.571 & 0.57 & 0.5579 & 0.5579 & 0.5711 & 0.5711 \\
\hline 10 & 0 & 0.75 & 0.3206 & 0.3204 & 0.3166 & 0.3166 & 0.3195 & 0.3195 \\
\hline 11 & 0 & 0.8 & 0.1376 & 0.1375 & 0.1372 & 0.1372 & 0.1379 & 0.1379 \\
\hline 12 & 0 & 0.9 & 0.00154 & 0.001533 & 0.0016 & 0.00165 & 0.0015 & 0.0015 \\
\hline 13 & 0 & 0.92 & 0.00041 & 0.000411 & 0.00062 & 0.00062 & 0.0006 & 0.0006 \\
\hline 14 & 0 & 0.95 & 0 & 0 & 0 & 0 & 0 & 0 \\
\hline
\end{tabular}




\section{COMPARISON OF RECTANGLE, V AND U-SHAPE CHANNELS}

Analysis is done for $\mathrm{V}$ and $\mathrm{U}$ shape single channels in the Fluent. Results are shown in Table 4.1 as the function of voltage and current density keeping the temperature and pressure constant.

\begin{tabular}{|c|c|c|c|c|}
\hline \multirow{2}{*}{ S.No. } & \multicolumn{2}{|c|}{ Electric potential (V) } & \multicolumn{2}{c|}{ Current density (A/cm $\left.{ }^{2}\right)$} \\
\cline { 2 - 5 } & \multirow{2}{*}{$\mathbf{V}_{\text {anode }}$} & $\mathbf{V}_{\text {cathode }}$ & $\mathbf{I}_{\text {anode }}$ & $\mathbf{I}_{\text {cathode }}$ \\
\hline 1 & 0 & 0 & 3.259 & 3.044 \\
\hline 2 & 0 & 0.05 & 3.236 & 3.042 \\
\hline 3 & 0 & 0.1 & 3.204 & 3.037 \\
\hline 4 & 0 & 0.2 & 3.107 & 2.982 \\
\hline 5 & 0 & 0.3 & 2.954 & 2.868 \\
\hline 6 & 0 & 0.4 & 2.695 & 2.625 \\
\hline 7 & 0 & 0.5 & 2.286 & 2.236 \\
\hline 8 & 0 & 0.6 & 1.706 & 1.683 \\
\hline 9 & 0 & 0.7 & 0.571 & 0.57 \\
\hline 10 & 0 & 0.75 & 0.3206 & 0.3204 \\
\hline 11 & 0 & 0.8 & 0.1376 & 0.1375 \\
\hline 12 & 0 & 0.9 & 0.0015 & 0.0015 \\
\hline 13 & 0 & 0.92 & 0.0004 & 0.0004 \\
\hline 14 & 0 & 0.95 & 0 & 0 \\
\hline
\end{tabular}

V-I Curve

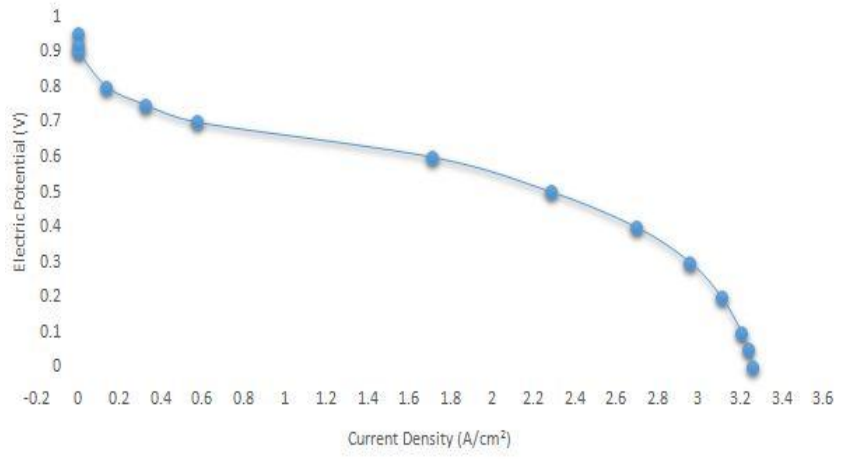

Figure 4.1 V-I curve on experimental result

\section{Summery}

Comparison of rectangular, semicircular, triangular channels are done by drawing the polarization curve for all the channels as shown in Fig 5.1\&5.2 which indicates the semicircular and triangular channels give better performance when compared with the rectangular channel.

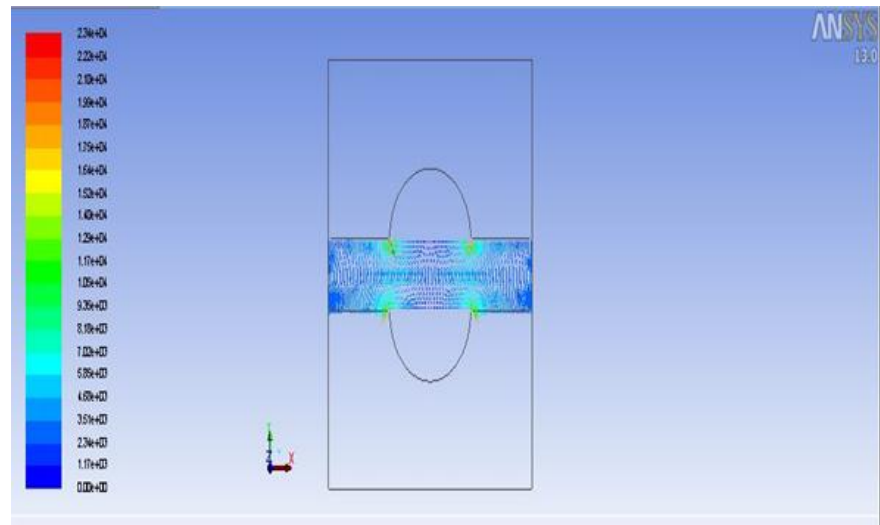

Figure 5.1 half round analysis viewer 


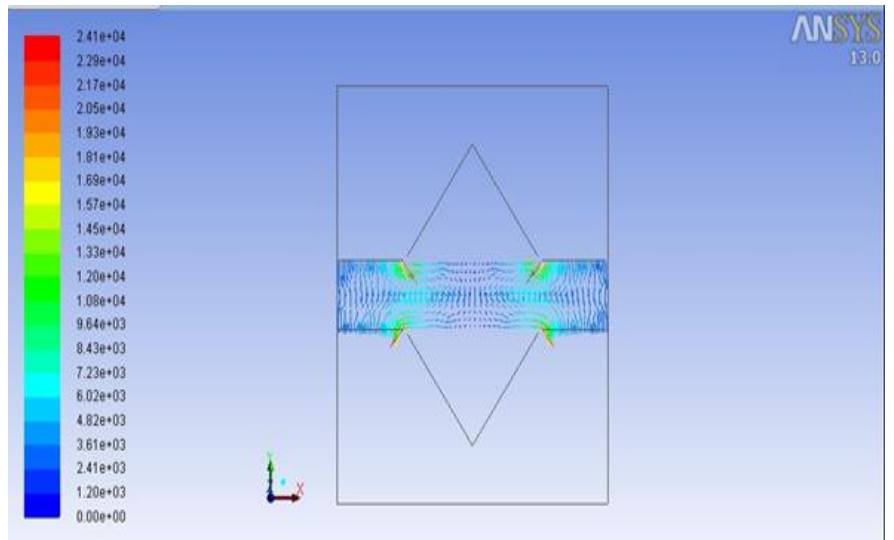

Figure 5.2 Triangular analysis viewer

The following conclusions can be drawn from the results.

1. The theoretical model developed for single PEM fuel cell simulates effectively the various conditions that exist in a real fuel cell.

2. The fuel cell performance is improved with a decrease in temperature from $70^{\circ} \mathrm{C}$ to $40^{\circ} \mathrm{C}$. This is due to increase of gas diffusivity, exchange current density and membrane conductivity at lower temperature.

3. As the operating pressure is increased from 0.5 to $2 \mathrm{bar}$, the fuel cell performance also increases due to increase in inlet concentration of oxygen.

4. The theoretical model is developed with different channel shape (Rectangle, $\mathrm{V}$ and $\mathrm{U}$ ) for PEM fuel cell.

5. Simulation results for $\mathrm{V}$ and $\mathrm{U}$ shapes showed an increase in hydrogen consumption over the rectangular shaped cross-section.

6. The use of such channels with proper dimensions will lead to increased hydrogen consumption at the anode, which in turn will lead to better fuel cell performance.

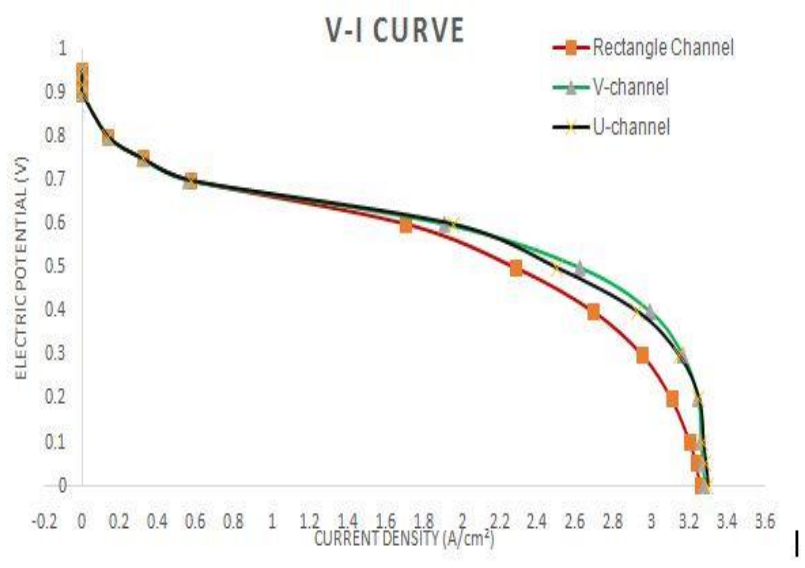

Figure 7 comparison curve -V-I position

\section{Future Scope For The Project}

The numerous research studies are going over the PEM fuel cell model. Most of the works are concentrated on the design and operating parameters influencing on the performance of the PEM fuel cell.

We could also reveal the influence of channel cross section, flow channel like serpentine, interdigitated on the behavior of the fuel cell. The theoretical model analysis could be done on the multi pass channel using the procedure developed for the interdigit model in this project.

\section{References}

[1]. J.G. Carton, V. Lawlor,A.G. Olabi, C.HochenauerG. Zauner Water droplet accumulation and motion in PEM(Proton Exchange Membrane) fuel cell mini-channels.

[2]. P.K. Jithesh, A.S. Bansode, T.Sundararajan ,Sarit K. Das The effect of flow distributors on the liquid water distribution and performance of a PEM fuel cell

[3]. K.B. Shyam Prasad, S. Maharudrayya, S. Jayanti Flow maldistribution in interdigitated channels used in PEM fuel cells 
[4]. Wei-Mon Yan, Sheng-Chin Mei, Chyi-Yeou Soong, Zhong-Sheng Liu, Datong Song Experimental study on the performance of PEM fuel cells with interdigitated flow channels

[5]. Xun-Liang Liu, Ya-Wei Tan, Wen-Quan Tao, Ya-Ling He A hybrid model of cathode of PEM fuel cell using the interdigitated gas distributor .

[6]. Xiao-Dong Wang, Yuan-Yuan Duan, Wei-Mon Yan, Xiao-Feng Peng Effects of flow channel geometry on cell performance for PEM fuel cells with parallel and interdigitated flow fields.

[7]. J.P. Owejan, T.A. Trabold, D.L. Jacobson, D.R. Baker, D.S. Hussey, M. ArifIn situ investigation of water transport in an operatingPEM fuel cell using neutron radiography: Part 2 - Transient water accumulation in an interdigitated cathode flow field.

[8]. Anh Dinh Le, Biao Zhou A generalized numerical model for liquid water in a proton exchange membrane fuel cell with interdigitated design.

[9]. Supaporn Therdthianwong Vilasinee Thitakamol Apichai Therdthianwong Mid-baffle interdigitated flow fields for proton exchange membrane fuel cells 